\title{
Advances in the pathogenesis of primary and secondary haemophagocytic lymphohistiocytosis: differences and similarities
}

\author{
Ellen Brisse, ${ }^{1}$ Carine H. Wouters ${ }^{2, *}$ and Patrick Matthys ${ }^{1, *}$ \\ ${ }^{1}$ Laboratory of Immunobiology, Rega Institute, KU Leuven, Leuven, Belgium and ${ }^{2}$ Laboratory of Paediatric Immunology, KU Leuven, \\ University Hospital Gasthuisberg, Leuven, Belgium
}

\begin{abstract}
Summary
Haemophagocytic lymphohistiocytosis (HLH) comprises a heterogeneous spectrum of hyperinflammatory conditions that are inherited (primary HLH) or acquired in a context of infections, malignancies or autoimmune/autoinflammatory disorders (secondary HLH). Genetic defects in the cytotoxic machinery of natural killer and $\mathrm{CD} 8^{+} \mathrm{T}$ cells underlie primary HLH, with residual cytotoxicity determining disease severity. Improved sequencing techniques have expanded the range of causal mutations and have redefined many cases of secondary HLH as primary HLH and vice versa, blurring the distinction between both subtypes. These insights allow HLH to be conceptualized as a threshold disease, in which interplay between various genetic and environmental factors causes progressive inflammation into a critical point, beyond which uncontrolled activation of immune cells and excessive cytokine production give rise to the cardinal symptoms of HLH. Various pathogenic pathways may thus converge to a common end stage of fulminant HLH.
\end{abstract}

Keywords: Haemophagocytic syndrome, haemophagocytic lymphohistiocytosis, macrophage activation syndrome, pathogenesis, genetics.

Haemophagocytic lymphohistiocytosis (HLH) is a rare, lifethreatening syndrome caused by uncontrolled activation of lymphocytes and macrophages. Characteristic symptoms are presented in Table I. A genetic and an acquired form, termed primary and secondary HLH, are distinguished. The former is caused by mutations in genes regulating granule-dependent cytotoxicity of natural killer (NK) cells and cytotoxic T lymphocytes (CTLs), the latter presents without a familial history

Correspondence: Patrick Matthys, Laboratory of Immunobiology, Rega Institute, KU Leuven, Minderbroedersstraat 10, B-3000 Leuven, Belgium

E-mail: patrick.matthys@kuleuven.be

${ }^{\star}$ These authors contributed equally. as a complication of various conditions (Janka \& Lehmberg, 2014).

\section{Primary HLH}

Primary HLH is inherited in an autosomal recessive or Xlinked manner. Mutations in nine genes have been associated with HLH so far. The encoded proteins play non-redundant roles in granule effector protein synthesis or in the formation, trafficking, docking, priming and membrane fusion of cytotoxic granules (Usmani et al, 2013). Primary HLH patients with a diverse genetic background therefore share a common immunophenotype of decreased to absent cytotoxicity.

Based on the underlying mutations, five types of familial HLH (FHL-1 to FHL-5) and four immunodeficiency syndromes closely related to HLH are distinguished.

\section{Familial HLH type 1-5}

Mutations in PRF1, coding for the granule effector protein perforin (PRF1), were the first to be causally linked to primary HLH (Stepp et al, 1999). Today, 30-40\% of molecularly diagnosed patients possesses a mutation in PRF1, classifying them as FHL-2 (Cetica et al, 2016). Upon degranulation of CTLs or NK cells, perforin monomers are released into the immune synapse, where they polymerize in the target cell membrane to form pores, through which granzymes enter to induce apoptosis (Sieni et al, 2014; de Saint Basile et al, 2015).

Mutations in UNC13D are associated with FHL-3, affecting one-third of patients with primary HLH. UNC13D encodes Munc13-4, also termed UNC13D, which plays a non-redundant role in the priming of docked cytolytic granules, preparing the granules for membrane fusion. Munc13-4 does so by regulating the interaction between vesicle-SNARE (soluble N-ethyl-maleimide-sensitive-factor attachment protein receptor) and target $(\mathrm{t})$-SNARE proteins, required to form a SNARE complex enabling membrane fusion of cytotoxic vesicles. In addition to cytotoxicity, UNC13D mutations 
Table I. Overview of characteristic HLH symptoms

\begin{tabular}{ll}
\hline Clinical symptoms & Laboratory abnormalities \\
\hline Fever & Pancytopenia \\
Splenomegaly & Thrombocytopenia \\
Hepatomegaly & Anaemia \\
Lymphadenopathy & Neutropenia \\
Liver dysfunction & Lymphopenia \\
Bleeding diathesis & Leukopenia \\
Oedema & Hyperferritinaemia \\
Skin rash & Hypertriglyceridaemia \\
Central nervous system dysfunction & Hyperbilirubinaemia \\
Irritability, headaches, encephalopathy & Elevated liver enzymes \\
Ataxia, seizures, coma & Elevated lactate \\
Multi-organ failure & dehydrogenase \\
& Hypofibrinogenaemia \\
Histological features & Elevated D dimers \\
\hline Tissue infiltration of activated & Hypoalbuminaemia \\
immune cells & Hypoproteinaemia \\
Haemophagocytosis & Hyponatraemia \\
Disseminated intravascular coagulation & Reduced NK cell \\
& cytotoxicity \\
& Reduced CTL cytotoxicity \\
& Elevated soluble CD163 \\
& Elevated soluble CD25 \\
& Hypercytokinaemia \\
\hline &
\end{tabular}

CTL, cytotoxic T lymphocyte; NK, natural killer.

affect platelet granule exocytosis and neutrophil phagosome maturation, thus contributing to coagulopathy and impaired intracellular bacterial killing (Janka \& Lehmberg, 2014; Nakamura et al, 2015).

FHL-4 accounts for as few as $5 \%$ of FHL cases. It results from defects in syntaxin-11, a t-SNARE protein encoded by STX11, which regulates granule membrane fusion. The defect not only reduces the cytotoxic function of CTLs and NK cell, but also impairs neutrophil and platelet granule exocytosis, similar to FHL-3 (D’Orlando et al, 2013; Tang, 2015). Silencing of syntaxin-11 in human macrophages in vitro was found to increase engulfment of apoptotic and opsonized target cells, indicating a negative regulatory role for STX11 in haemophagocytosis (Zhang et al, 2008b).

FHL-5, representing 5-20\% of FHL cases, is caused by mutations in STXBP2, encoding Munc18-2, also termed syntaxin binding protein 2 (STXBP2) (de Saint Basile et al, 2015; Cetica et al, 2016). Munc18-2 interacts with syntaxin11 , together facilitating formation of the SNARE complex. Accordingly, deficiencies in Munc18-2 and syntaxin-11 result in similarly defective cytotoxicity. Interestingly, cytotoxic function in both FHL- 4 and FHL- 5 can be restored by interleukin 2 (IL2) stimulation, which enhances the levels of syntaxin-3 and Munc18-1, substituting for defective syntaxin-11 and Munc18-2, respectively (Hackmann et al, 2013). Nonetheless, the clinical presentation of FHL-5 differs from that of other FHL subtypes (Pagel et al, 2012), which is probably related to additional functions of STXBP2. Munc18-2 is involved in several degranulation processes, including platelet granule secretion, mast cell degranulation and neutrophil granule mobilization (Kostova et al, 2015). Many FHL-5 patients present with severe enteropathy, which results from defective Munc18-2 expression in intestinal and renal epithelium, causing membrane trafficking malfunction in gut and kidneys (Stepensky et al, 2013). Given that erythrocytes also express Munc18-2, FHL-5 patients possess an intrinsic erythroid defect, characterized by aberrant erythropoiesis, erythrocyte maturation and cell morphology, possibly contributing to anaemia (Kostova et al, 2015).

In the remaining $8-10 \%$ of FHL cases, suspected on the basis of familial history, parental consanguinity, or confirmed immunological deficiencies, the underlying molecular defects are yet to be determined (de Saint Basile et al, 2015; Cetica et al, 2016). This subgroup includes patients with FHL-1, in which the causative mutation is located on chromosome 9 (9q21.1). The causal gene and corresponding protein have not yet been identified (Ohadi et al, 1999).

\section{Primary immunodeficiency syndromes associated with HLH}

Griscelli syndrome type 2, Chédiak-Higashi syndrome and Hermansky-Pudlak syndrome type 2. Griscelli syndrome type 2 (GS2), Chédiak-Higashi syndrome (CHS) and HermanskyPudlak syndrome type 2 (HPS2) present with overall defects in the trafficking and exocytosis of secretory lysosomes. Given that lysosomes exert important functions in multiple cell types, including neurons, melanocytes, platelets, granulocytes, T and NK cells, these defects can result in progressive neurological disease, impaired pigmentation, compromised platelet clotting, neutropenia, decreased granulocyte function and defective cytotoxicity (Dotta et al, 2013). As the mutations underlying FHL-3, -4 and -5 also affect exocytosis processes other than cytolytic degranulation, including platelet and neutrophil secretions, the traditional distinction between FHL and the immunodeficiency syndromes associated with HLH has become an artificial one (Janka \& Lehmberg, 2014).

GS2 is linked to mutations in $R A B 27 A$, which codes for a GTPase that directly interacts with Munc13-4. This interaction is mandatory for the docking of cytotoxic granules at the plasma membrane. RAB27A also appears to regulate the polarized transport of granules towards the docking site (Dotta et al, 2013; Usmani et al, 2013; Sieni et al, 2014).

Mutations in LYST are responsible for defective formation, maturation and function of different secretory lysosomes in CHS. LYST (lysosomal trafficking regulator) regulates protein trafficking towards, and protein sorting in, lysosomes. Deficiency results in giant intracytoplasmic lysosomes in melanocytes, neurons, neutrophils, monocytes, eosinophils, NK cells and lymphocytes, possibly hampering vesicle transport along 
the microtubule cytoskeleton and obstructing exocytosis (Dotta et al, 2013; Sieni et al, 2014).

Hermansky-Pudlak syndrome type 2 is caused by mutations in $A P 3 B 1$, encoding the $\beta 3 \mathrm{~A}$ subunit of adaptor protein 3 (AP3). AP3 is part of a complex regulating recruitment and protein sorting in lysosomes, like platelet dense granules, melanosomes, osteoclast granules and cytotoxic granules. Defects compromise the function of secretory lysosomes and impair antigen presentation, NKT cell development and the microtubule-guided movement of lysosomes towards the immune synapse. Thus, AP3B1 mutations explain the defective cytotoxic function of CTLs and NK cells in all HPS2 patients examined to date. Nonetheless, HLH has been described in only 2 patients so far, of which one also carried a heterozygous RAB27A mutation (Enders et al, 2006; Jessen et al, 2013a). Hence, the contribution of AP3B1 mutations to HLH susceptibility requires further clarification.

X-linked lymphoproliferative disease. In X-linked lymphoproliferative disease (XLP), no severe defects in NK cell or CTL cytotoxic function are present, as the causal mutations do not directly affect the proteins involved in granule-mediated cytotoxicity (Bryceson et al, 2012; Usmani et al, 2013). Instead, XLP is characterized by extreme susceptibility to Epstein-Barr virus (EBV), with the first encounter usually provoking HLH. Patients also carry a higher risk of EBVassociated lymphomas (Janka \& Lehmberg, 2014).

Mutations causing XLP-1 have been localized to SH2D1A, encoding signalling lymphocyte activation molecule (SLAM)associated protein (SAP), also termed $\mathrm{SH} 2$ domain-containing 1A. SAP predominantly interacts with activating receptor 2B4 on NK cells, stimulating cytotoxicity. In $\mathrm{T}$ and $\mathrm{B}$ cells it binds to costimulatory SLAM molecules, promoting their effector function. Hence, lack of SAP depresses NK and CTL function and is thought to result in NKT cell deficiency as well. The remarkable susceptibility to EBV has been explained by a selective cytotoxic impairment of SAP-deficient CTLs towards infected B cells. In the absence of SAP, the CTL response to Bcell-mediated antigen presentation is defective, resulting in a failure to control EBV infection (Palendira et al, 2011; Sieni et al, 2014; Brisse et al, 2015; de Saint Basile et al, 2015).

XLP-2 is linked to loss-of-function mutations in XIAP (BIRC4), encoding X-linked inhibitor of apoptosis (XIAP). As XIAP inhibits the activity of different caspases, cells of XIAP-deficient patients show higher apoptosis rates in vitro. Accordingly, XIAP mutations are assumed to increase lymphocyte susceptibility to activation-induced cell death, which may appear paradoxical in the event of $\mathrm{HLH}$, typically characterized by excessive lymphocyte proliferation and activation. Since XIAP-deficient T and NK cells display apparently normal in vitro cytotoxic functions, HLH development in XLP-2 may be linked to other pathogenic processes, such as accumulating apoptotic cells and persisting EBV-infected cells, triggering excessive immune activation (Marsh et al, 2010; de Saint Basile et al, 2015). XLP-associated HLH was previously assumed to occur only in males, however, two HLH cases have recently been reported in female patients carrying a heterozygous XIAP mutation that significantly reduced XIAP expression due to highly skewed X-chromosome inactivation of the wild-type allele (Holle et al, 2015; Yang et al, 2015).

\section{Genotype/phenotype correlations in primary $\mathrm{HLH}$}

Advances in genetic screening have driven an on-going discovery of 'atypical' mutations in primary HLH that are associated with delayed onset and/or an attenuated phenotype (Zhang et al, 2011, 2014a). These 'atypical' mutations have expanded the perception of primary HLH, formerly considered a disorder restricted to babies and young infants, to include patients of all ages.

The relationship between genotype and phenotype in primary HLH has been extensively investigated using mouse models. Comparative studies of murine primary HLH, induced by viral infection, revealed a range of severities that were inversely correlated with residual cytotoxicity. $\mathrm{Prfl}^{-/-}$ mice, having the most profound cytotoxic impairment, displayed a fatal, full-blown HLH syndrome, closely followed in severity by $R a b 27 a^{-1-}$ mice. After a severe acute phase of disease, Stx $11^{-1-}$ mice progressed into a chronic, attenuated stage, while souris $\mathrm{Lyst}^{-/-}$mice showed a mild phenotype from the onset of disease. HLH in $A p 3 b 1^{-1-}$ mice was only transient and beige Lyst ${ }^{-/-}$mice exhibited few, if any, HLHlike symptoms (Jessen et al, 2013a,b; Sepulveda et al, 2013). Noteworthy, both beige and souris mice represent a model for CHS, but carry different Lyst mutations. NK cell cytotoxicity is equally depressed, but the beige mutation impairs CTL function considerably less than the souris mutation, explaining the lack of HLH features in beige mice and supporting the theory of residual CTL cytotoxicity as a key determinant of HLH development (Jessen et al, 2011).

In primary $\mathrm{HLH}$ patients, disease severity, as estimated by the age of disease onset, was found to be determined by the mutated gene and the nature of the mutation (Jessen et al, 2011, 2013b).

Classic cases of primary HLH are caused by biallelic, recessive mutations in the coding sequence of any of the nine aforementioned genes. In these cases, homozygous nonsense or null mutations result in absent or barely detectable levels of the encoded proteins, predisposing to early-onset, severe HLH. Considering biallelic loss-of-function mutations, a gradation in the age of presentation was distinguished from earliest onset in FHL-2 to moderately early onset in GS2 and FHL-3, intermediate onset in FHL-4 and generally later presentation in CHS and HPS2. The age of onset was inversely correlated with the residual cytotoxic function of the patients' CTLs, reflecting the murine data (Horne et al, 2008; Jessen et al, 2013b; Sepulveda et al, 2013).

Nonsense mutations are rare in atypical, late-onset primary HLH. Rather, 'milder' missense mutations are detected 
(Zhang et al, 2011; Wang et al, 2014; Tesi et al, 2015a; Cetica et al, 2016), causing partial impairment of protein function or decreased protein production. Additionally, mutations may be found outside of the coding sequence, in evolutionary conserved noncoding regions, including splice-site mutations, resulting in transcript defects, and mutations in intronic transcription regulatory regions, disrupting transcription factor binding (Pagel et al, 2012; Entesarian et al, 2013; Meeths et al, 2014; Qian et al, 2014; Zhang et al, 2014b). Deep intronic mutations are particularly abundant in FHL-3 patients (Qian et al, 2014).

Instead of monogenic homozygous defects, monogenic compound heterozygous mutations may predispose to lateonset primary HLH (Zhang et al, 2011). Bigenic or polygenic heterozygous mutations have also been reported. Additive effects are plausible, because all FHL genes are involved in the same cytolytic pathway. Heterozygous mutations that each partially impair cytotoxic function may generate a 'gene dosage' effect through synergy (Zhang et al, 2011, 2014a). This was corroborated by the generation of polygenic mouse models, in which the accumulation of heterozygous mutations in Rab27a, Prf1 and/or Stx11 reduced cytotoxic function and increased the risk of developing virus-induced HLH (Sepulveda et al, 2016). Heterozygous mutations in X-linked genes may also cause HLH in female patients, depending on the percentage of wild-type $\mathrm{X}$-chromosome inactivation (Holle et al, 2015; Yang et al, 2015). Moreover, monoallelic missense mutations in STXBP2 or RAB27A have been described to cause late-onset FHL in a (partial) dominantnegative manner (Spessott et al, 2015; Zhang et al, 2016). These findings stretch the traditional notion of primary HLH as a monogenic, homozygous recessive disorder.

It was recently hypothesized that a so-called 'second-hit' mechanism, involving non-HLH-related mutations, could synergize with cytotoxicity-affecting mutations to induce late-onset primary HLH. Homozygous mutations in PCDH18, increasing activation and reducing apoptosis of CTLs, on top of compound heterozygous PRF1 mutations, were reported to co-trigger FHL-2 (Gao et al, 2016).

Together, murine and patient data indicate a continuum of primary HLH in which the genotype, i.e. affected genes and the nature of mutations, translates into a so-called 'immunotype', with variable residual cytotoxicity, that is linked to a gradient of phenotypes in disease severity (Jessen et al, 2011, 2013b). This concept is illustrated in Fig 1.

\section{Pathogenesis of primary $\mathrm{HLH}$}

Animal models of primary HLH have been valuable tools for unravelling the role of specific proteins in the degranulation machinery and in HLH pathophysiology. In murine primary $\mathrm{HLH}$, a major pathogenic role has been attributed to hyperactivated CTLs and their $\gamma$-interferon (IFN- $\gamma$ ) secretion (Jordan et al, 2004; Pachlopnik Schmid et al, 2009; Kögl et al, 2013). The activated CTLs infiltrate multiple organs while producing large amounts of IFN- $\gamma$ that mediates secondary activation of macrophages, and possibly also fibroblasts and endothelial cells (Billiau et al, 2005; Put et al, 2015). In turn, these cells secrete cytokines, such as IL1 $\beta$, IL6 and tumour necrosis factor $\alpha(\mathrm{TNF} \alpha)$, culminating in a cytokine storm (Jenkins et al, 2015). Several feedback mechanisms were identified that normally function to limit this inflammatory escalation, but are deficient in primary HLH.

Persistent antigenaemia. The first, well-known effector function of CTLs and NK cells is the clearance of infected cells and tumour cells. When cytotoxic function is impaired, proliferation of cancerous cells is unrestrained and infectious triggers fail to be eliminated. The source of antigenic stimulation persists and drives continuous activation and expansion of antigen-specific $\mathrm{T}$ cells.

Ongoing antigen presentation. A second effector function of CTLs ensures essential immunoregulation via a negative feedback loop, limiting on-going antigenic stimulation. Through perforin-dependent killing of a rare subset of antigen-presenting dendritic cells, CTLs suppress prolonged antigen presentation, thus preventing further $\mathrm{T}$ cell activation. In primary HLH, these dendritic cells persist and increase their antigen presentation, resulting in uncontrolled CTL activation (Lykens et al, 2011; Terrell \& Jordan, 2013).

Regulatory NK cells. NK cells exert a similar immunoregulatory function in primary HLH. Depletion experiments designated no pathogenic role to NK cells in murine HLH (Jordan et al, 2004; Kögl et al, 2013). Instead, models in which cytotoxic defects were restricted to either NK cells or CTLs indicated that functioning NK cell cytotoxicity is sufficient to limit hyperactivation and excessive proliferation of CTLs and to protect from severe HLH pathology (Sepulveda et al, 2015).

Regulatory $T$ cells. Another immunoregulatory mechanism, involving regulatory $\mathrm{T}$ cells (Tregs), may be defective in primary HLH. Tregs eliminate activated autologous CTLs in a perforin- and granzyme-dependent way to curb inflammation (Verbsky \& Grossman, 2006). In normal conditions, Tregs also indirectly suppress CTL proliferation by preferentially consuming the available IL2. However, Treg homeostasis was reported to be disturbed in murine FHL-2. Reduced production of IL2 and elevated levels of antagonistic soluble CD25 limited the availability of IL2. The remaining free IL2 was preferably consumed by hyperactivated CTLs, that upregulated their CD25 expression to surpass that of Tregs, inverting the IL2 consumption hierarchy and resulting in a profound collapse of Treg numbers (Humblet-Baron et al, 2016).

Hypercytokinaemia. Recently, a direct role for defective granule-mediated cytotoxicity in the development of the 


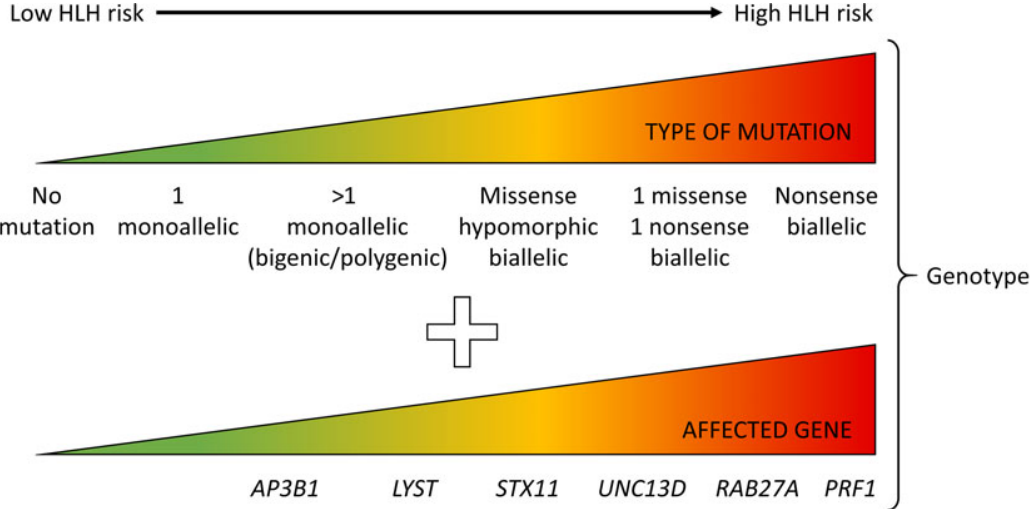

Fig 1. Genotype-phenotype correlations in primary HLH. The type of mutation and affected gene determine the extent of the cytotoxic defect in patients. Different genetic combinations (genotype) result in a gradient of remaining cytotoxic function (immunotype) that correlates with the age of disease onset and disease severity (phenotype). HLH, haemophagocytic lymphohistiocytosis.

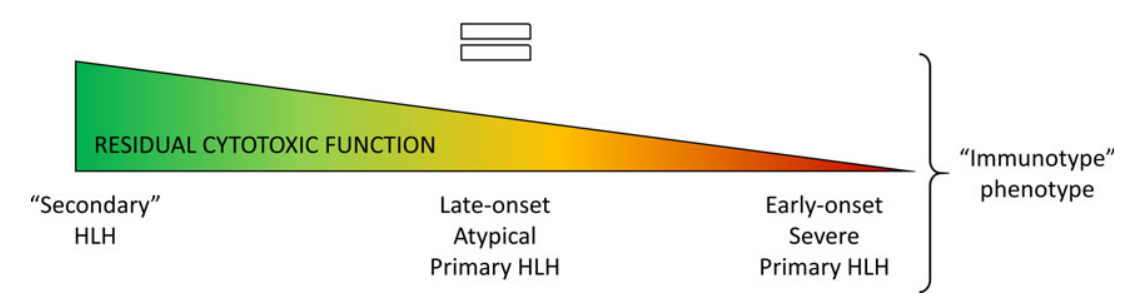

cytokine storm was unravelled. Cytolytically impaired NK cells and CTLs failed to disengage from their targets, as the detachment signal needed to come from the dying target cell, increasing mean contact times up to fivefold. Prolonged synapse duration stimulated the effector cells through repetitive $\mathrm{Ca}^{2+}$-signalling to secrete increasing amounts of cytokines and chemokines, including IFN- $\gamma$, that directly activated macrophages, linking cytotoxicity defects to hypercytokinaemia and initiation of systemic inflammation (Jenkins et al, 2015).

IFN- $\gamma$ is considered the major driver of pathology in murine primary $\mathrm{HLH}$, directly inducing haemophagocytosis and pancytopenia (Jordan et al, 2004; Pachlopnik Schmid et al, 2009; Zoller et al, 2011). Evidence for a similar role in humans is less robust. Elevated IFN- $\gamma$ levels are often present in the sera of primary HLH patients, but not in all patients, and reported levels vary widely (Henter et al, 1991; Osugi et al, 1997; Nagasawa et al, 2008; Xu et al, 2012). Furthermore, microarray analysis of peripheral blood mononuclear cells from primary HLH patients revealed no significant upregulation of IFN- $\gamma$ expression and a peculiar absence of IFN- $\gamma$-induced gene expression. This unexpected finding might be explained by the upregulation of suppressor-ofcytokine-signalling-3 (SOCS-3) in patients, which decreases responsiveness of macrophages to IFN- $\gamma$, or by downregulation of IFN- $\gamma$ receptor 2 . In contrast, pathways related to IL1, IL6, IL8 and IL10 signalling were significantly upregulated, signifying that, rather than one central player, multiple cytokines synergize to enhance disease in human HLH (Sumegi et al, 2011).

Alarmins. Recently a novel cytokine was implicated in the pathogenesis of murine FHL-2. IL33, a member of the IL1 superfamily, is released from non-haematopoietic cells upon cellular stress or necrosis, as an alarmin. It can be endocytosed by lymphocytes to initiate inflammation. IL33 thus stimulates CTL activation and IFN- $\gamma$ production (Rood et al, 2016). Interestingly, the IL33 receptor, ST2, signals through a myeloid-differentiation-primary-response-gene-88 (MyD88)-dependent pathway. This adaptor protein, required for signalling by IL1 family cytokines and downstream of most toll-like receptors (TLRs), was already considered a potential therapeutic target in murine FHL-3 (Krebs et al, 2011). The therapeutic efficacy of blocking ST2 signalling in murine FHL-2 confirms involvement of the MyD88 pathway in primary HLH (Rood et al, 2016). The contribution of danger signals to primary HLH might be underestimated. Defective cytotoxicity prevents target cells to be removed via the immunologically silent process of apoptosis. Instead, cell death through pyroptosis or necrosis will occur, resulting in the release of alarmins, instigating additional inflammation (Palmblad et al, 2014). Thus, two pathogenic processes possibly synergize to initiate disease in primary HLH: persistent antigen presentation perpetuates infectious inflammation, while alarmins effectuate non-infectious inflammation (Palmblad et al, 2014; Rood et al, 2016).

In conclusion, granule-mediated cytotoxicity is not only vital for the control of infections and cancers, it exerts equally essential immunoregulatory functions that limit antigen presentation, restrict CTL activation and regulate cytokine production. Lastly, induction of apoptosis constitutes an indispensable, immunologically silent process of cell death. The hypothesis on primary HLH pathogenesis is depicted in Fig 2.

\section{Secondary HLH}

Secondary HLH is clinically identical to primary HLH, but defined by a lack of family history or (known) genetic defects 
in cytotoxicity, and instigated by events that disrupt immune homeostasis. Numerous triggering infections and underlying inflammatory disorders have been reported, resulting in the further subdivision of infection-associated, malignancy-associated and autoinflammation/autoimmunity-associated forms, described below. Secondary HLH can also arise in acquired immunodeficiencies, following chemotherapy, immunosuppression, biological therapy and organ or stem cell transplantation, events known to imbalance the immune system (Atteritano et al, 2012; Janka \& Lehmberg, 2014; Ramos-Casals et al, 2014). Rare cases are also described in inborn metabolic disorders like lysinuric protein intolerance or biotinidase deficiency. Secondary HLH in metabolic patients is often atypical, lacking fever or including nonHLH features like vomiting or acidosis (Janka \& Lehmberg, 2014).

\section{Infection-associated secondary HLH}

Infection-associated HLH accounts for approximately half of all adult HLH cases (Ramos-Casals et al, 2014).

Viruses. A wide spectrum of viruses can elicit HLH. Herpesviruses lead the ranks, predominantly EBV, both in primary and secondary HLH. Around $60 \%$ of reported infectious cases coincide with primary infection or reactivation of latently present herpesviruses (Ramos-Casals et al, 2014). EBV classically infects B cells and nasopharyngeal epithelial cells, but in HLH it often infects CTLs or, less frequently, NK cells (Kasahara et al, 2001). This peculiar feature must be kept in mind when considering treatment of EBVassociated HLH with B-cell targeting rituximab. EBV viral load is considered a prognostic factor and correlates with disease severity in patients. Up to $10^{4}$ times higher viral titres are detected in EBV-associated HLH, compared to infectious mononucleosis. A predisposition to EBV-HLH appears to be present in Asia. Some have theorized a more virulent strain could underlie the higher incidence, others report no predominance of particular substrains (Kasahara et al, 2001; Teramura et al, 2002; Rouphael et al, 2007; George, 2014).

Aside from EBV, predominantly cytomegalovirus, but also herpes simplex virus (HSV), human herpesvirus-6 and -8, varicella zoster, parvovirus B19 and adenoviruses are known to trigger HLH. Less frequently, HLH is elicited by RNA viruses, including influenza and enteroviruses. Patients suffering human immunodeficiency virus (HIV) infection are prone to develop HLH upon opportunistic infections (Rouphael et al, 2007; George, 2014; Ramos-Casals et al, 2014). Recently, the resemblance of viral haemorrhagic fever, induced by Ebola virus, hantavirus or dengue virus, to HLH has been described (Cron et al, 2015).

Bacteria, parasites and fungi. Bacteria induce approximately $9 \%$ of reported adult HLH cases. Most commonly, HLH is associated with Mycobacterium infection, even vaccination with the attenuated Bacillus Calmette-Guérin may trigger HLH. Less frequently, HLH can arise during infections with Rickettsia, Staphylococcus, Ehrlichia, Mycoplasma and others.

Parasitic infections account for nearly $2.5 \%$ of adult HLH cases. The most potent protozoan trigger is Leishmania; in particular, visceral leishmaniasis progresses to HLH. Plasmodium and Toxoplasma can also elicit HLH.

More sporadically, fungi can induce HLH episodes, mostly in immunocompromised individuals, including patients with HIV, primary immunodeficiency or post-transplantation. Cases associated with Histoplasma, Candida and Cryptococcus have been described, amongst others (Rouphael et al, 2007; George, 2014; Ramos-Casals et al, 2014).

\section{Malignancy-associated secondary $H L H$}

HLH complicating malignancies is predominantly regarded a challenge of adult haematology/oncology, accounting for 15$50 \%$ of adult HLH cases. The likelihood of developing malignancy-associated HLH increases with age. Nonetheless, cases may be observed in children and adolescents. The most

Fig 2. Hypothesized pathogenesis of primary HLH. (A) Normal situation: 1. CTLs and NK cells eliminate tumour cells and/or infected cells via apoptosis. 2. When the immunological stimulus is cleared, the CTLs will inhibit further antigen presentation by removing antigen-presenting DCs. 3. Tregs compete with the activated CTLs for the available IL2 and thus limit the proliferation of CTLs. They may also directly eliminate activated CTLs. 4. NK cells likewise control the size of the activated CTL pool via induction of apoptosis. 5. This limits the amount of CTLderived IFN- $\gamma$ and consequently the extent of macrophage activation and additional cytokine production. (B) In the setting of primary HLH: $\mathbf{1 .}$ CTLs and NK cells fail to eliminate tumour cells and/or infected cells, which continue to replicate, resulting in persistent antigenaemia. 2. CTLs no longer remove the antigen-presenting DCs, leading to prolonged and heightened antigen presentation, stimulating antigen-specific $\mathrm{T}$ cells. 1+2. The inability of CTLs and NK cells to eliminate target cells causes an increase in synapse time, stimulating the effector cells to produce more cytokines. 3. Tregs can no longer outcompete the hyperactivated CTLs for the lower amount of available IL2 because the expression of CD25 is more highly upregulated in the latter. Treg numbers drop and CTLs continue to proliferate. 4. Similarly, lacking their cytotoxic capacity, NK cells no longer control the size of the activated CTL pool. 5. The activated CTLs produce massive amounts of IFN- $\gamma$ inducing excessive macrophage activation and directly provoking haemophagocytosis. In turn, the activated macrophages produce enormous amounts of pro-inflammatory cytokines, creating a cytokine storm. 6. As cells can no longer be eliminated via immunologically silent apoptosis, necrosis and/or pyroptosis will occur, resulting in the release of DAMPs that instigate further inflammation. Solid black arrows indicate the effective function of the processes as described by the numbers written above them (A), dotted black arrows indicate impaired function of these processes (B). Red arrows refer to the competition for available IL2 consumption (A+B). HLH, haemophagocytic lymphohistiocytosis; CTL, cytotoxic T lymphocyte; DAMP, dangerassociated molecular pattern; DC, dendritic cell; $\mathrm{M} \varphi$, macrophage; MHC, major histocompatibility complex; NK, natural killer; RBC, red blood cell; Treg, regulatory T cell. 


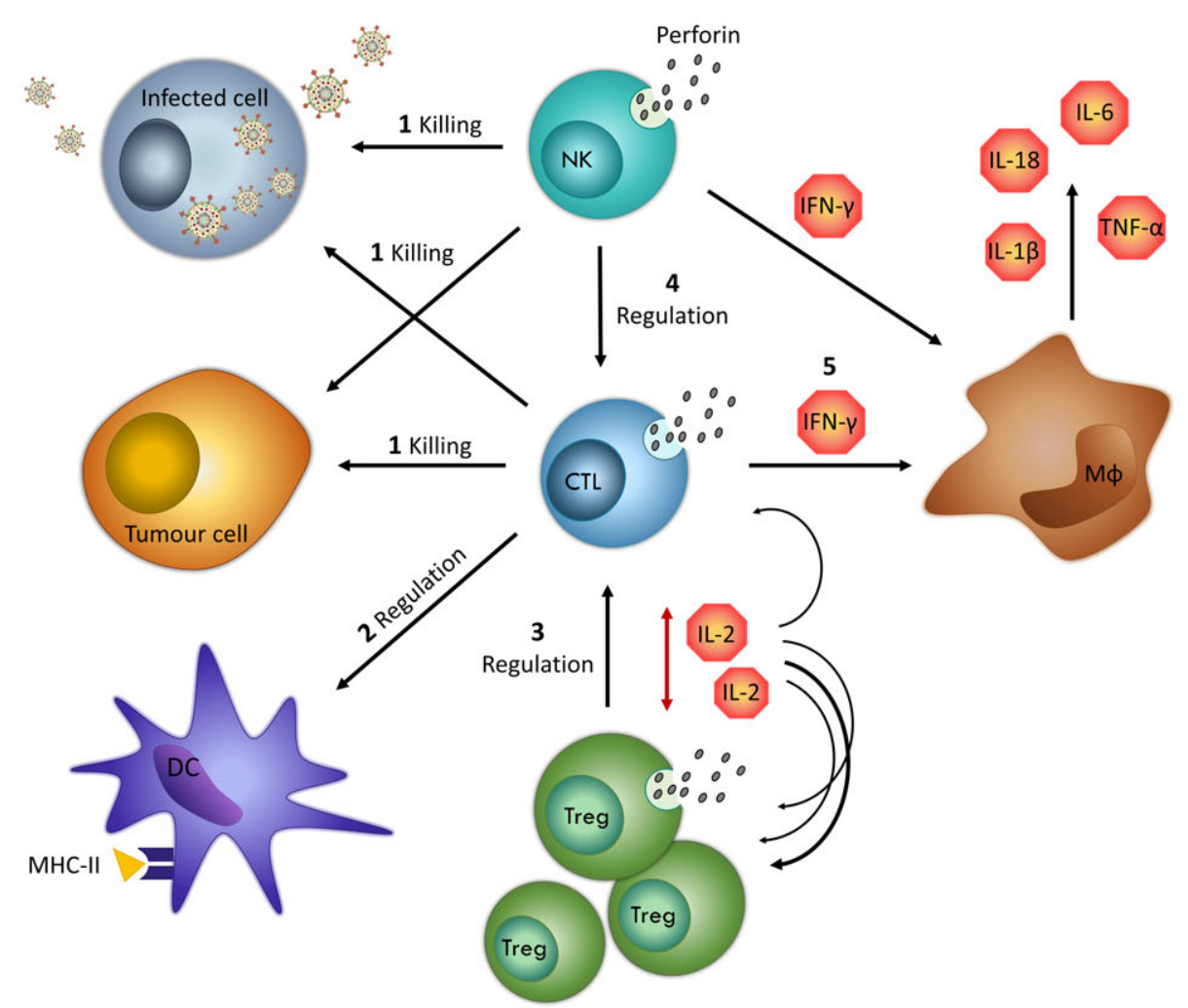

(B) HLH setting

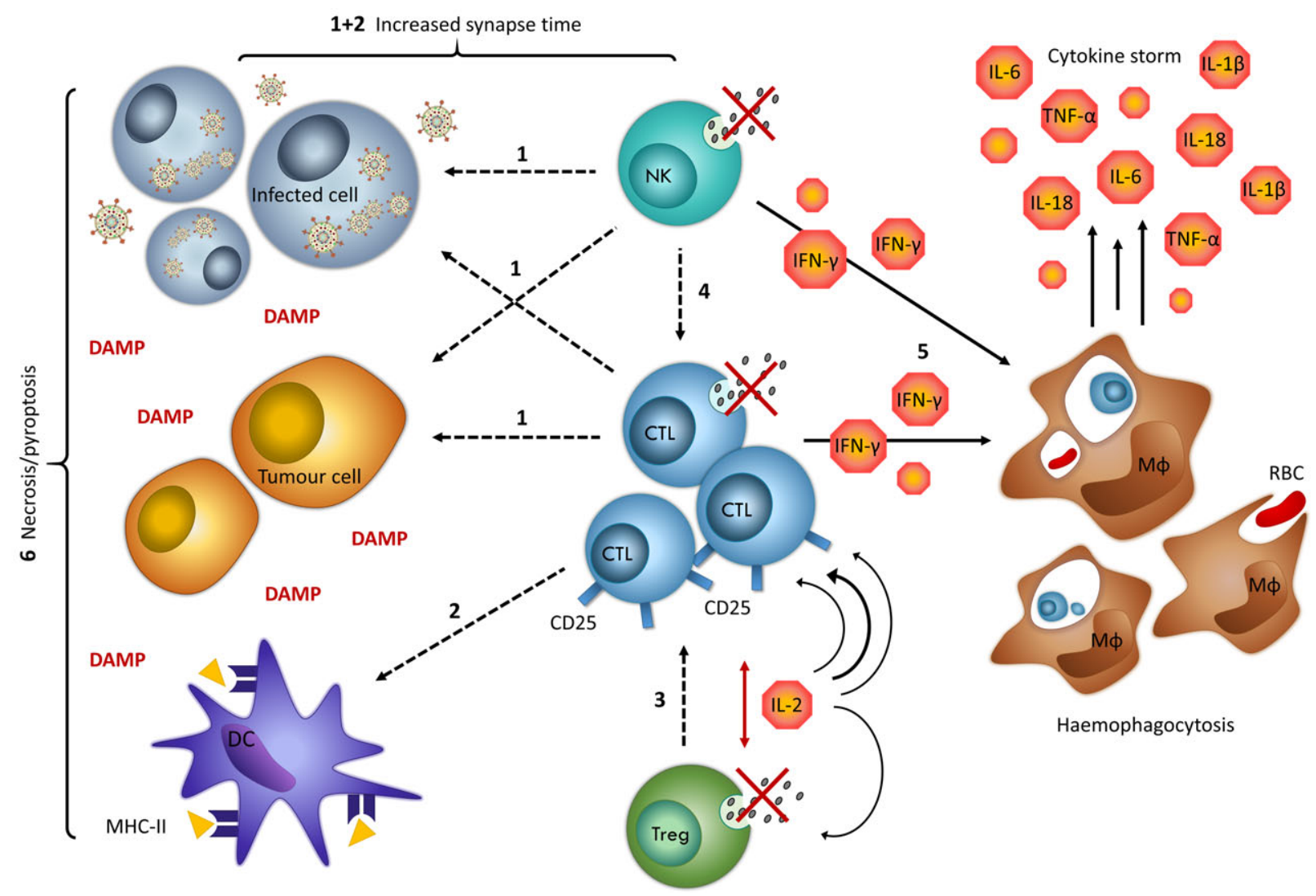


common underlying cancers are lymphomas, mostly T/NK cell, but also B cell lymphomas, and leukaemia. Association with solid tumours is rare. The neoplasm itself might trigger HLH, with aberrant cytokine production by malignant cells constituting a pathophysiological mechanism. Conversely, HLH may occur during chemotherapy, induced by infections, linking disease onset to therapy-induced immunosuppression. Often, EBV is involved, either as a co-trigger or causing the underlying malignancy. Interestingly, HLHrelated mutations can predispose to both haematological malignancies and HLH (George, 2014; Ramos-Casals et al, 2014; Lehmberg et al, 2015a,b; Löfstedt et al, 2015).

\section{Secondary HLH associated with autoimmune or autoinflammatory diseases}

Secondary HLH complicating autoimmune and autoinflammatory disorders is most frequently reported in systemic juvenile idiopathic arthritis (sJIA). $10 \%$ of sJIA patients develops clinically overt HLH, while $50 \%$ shows subclinical evidence of HLH. Secondary HLH also occurs in systemic lupus erythematosus, adult-onset Still's disease, Kawasaki disease and, sporadically, in rheumatoid arthritis, dermatomyositis, sarcoidosis, systemic sclerosis, polyarteritis nodosa and inflammatory bowel disease. HLH complicating rheumatological conditions is often referred to as 'macrophage activation syndrome' (MAS) (Atteritano et al, 2012; RamosCasals et al, 2014; Zhang et al, 2014b).

\section{Pathogenesis of secondary HLH}

Acquired defects in cytotoxicity. Compared to primary HLH, the pathophysiological mechanisms driving secondary HLH remain incompletely understood. Patients can exhibit reduced NK cell and/or CTL cytotoxicity, similar to primary HLH. This has been attributed to decreased perforin expression in some cases and reduced numbers of peripheral blood NK cells in others. However, in secondary HLH, the NK cell dysfunction is not intrinsic but acquired. It is a transient defect that typically normalizes with disease remission or reverses upon IL2 stimulation in vitro (Grom et al, 2003; Ramanan \& Schneider, 2003; Grom, 2004; Bryceson et al, 2012).

The cytokine storm is hypothesized to impair NK cell cytotoxicity in secondary HLH. Persistent high levels of otherwise NK cell-stimulating cytokines, like IL12 or IL18, might overactivate NK cells, predisposing to activationinduced apoptosis, or cause exhaustion and insensitivity to further cytokine stimulation (Avau et al, 2015; Canna \& Goldbach-Mansky, 2015). Recent evidence indicates chronic IL6 exposure is involved. Perforin and granzyme B expression of NK cells was reduced in IL6-overexpressing mice, resulting in defective cytotoxicity. Treatment of human NK cells with tocilizumab, an anti-IL6 antibody, increased perforin and granzyme B expression, enhancing their cytotoxic capacity (Cifaldi et al, 2015).
In addition to continuous cytokine exposure, several infectious agents are capable of suppressing CTL and/or NK cell cytotoxicity. The latent-membrane-protein-1 of EBV is capable of inhibiting SAP expression in T cells, creating a setting reminiscent of XLP1-associated HLH (Chuang et al, 2005). The haemagglutinin protein of $\mathrm{H} 5 \mathrm{~N} 1$ influenza reduces perforin expression in CTLs, impairing their cytotoxicity and allowing the persistence of stimulatory $\mathrm{H} 5$ antigen-presenting dendritic cells (Hsieh \& Chang, 2006). H1N1 influenza is described to infect and replicate in human NK cells and to induce apoptosis, contributing to decreased NK cell numbers and cytotoxic function (Mao et al, 2009). Many viruses encode anti-apoptotic proteins that delay apoptosis of infected cells, which was recently linked to prolonged cytotoxic synapse duration and cytokine hypersecretion, contributing to HLH pathogenesis (Jenkins et al, 2015). Amongst others, EBV and HSV-1 can render cells resistant to CTL-induced apoptosis (Jerome et al, 1998). Similarly, tumour cells are often resistant to apoptosis, thus prolonged synapse formation could also contribute to malignancy-associated HLH (Jenkins et al, 2015).

Innate immune activation. Although acquired defects in CTL and/or NK cell cytotoxicity have been described in secondary $\mathrm{HLH}$, the majority (approximately 75\%) of patients presents with normal cytotoxicity (Bryceson et al, 2012), indicating that alternative mechanisms can drive disease. Animal models of secondary HLH highlight the involvement of innate immune activation, through chronic or excessive stimulation of pattern recognition receptors like TLRs. Repeated stimulation of TLR9 resulted in several hallmark features of HLH in a mouse model of MAS. Depletion studies revealed no significant role for CTLs in this model, as opposed to their major role in primary HLH. Instead, disease was driven by overactivation of innate immune pathways (Behrens et al, 2011). Single, excessive stimulation of TLR9 was also reported to induce murine HLH, emphasizing the role of TLR activation in secondary HLH (Ohyagi et al, 2013). Notably, EBV also activates TLR9 signalling (Behrens et al, 2011).

Exaggerated signalling of TLRs has been connected to HLH pathogenesis in another model, in which IL6-transgenic mice display aberrant responses to TLR ligands. Constitutively high IL6 expression excessively amplified the inflammatory response to Poly(I:C), CpG, lipoteichoic acid and lipopolysaccharide, the latter inducing fulminant HLH. Thus, prolonged exposure to IL6, as observed in different autoimmune and autoinflammatory diseases, not only impairs NK cell cytotoxicity but also derails the immune system towards hyperinflammatory responses (Strippoli et al, 2012; Cifaldi et al, 2015).

Excessive inflammasome activation might also fuel inflammation in secondary HLH, as recently described in MAS patients carrying NLRC4 gain-of-function mutations. Such mutations result in caspase-1 overactivation, excessive IL18 production and systemic macrophage activation, underscoring the involvement of innate pathways in secondary HLH (Canna \& Goldbach-Mansky, 2015). 
Role of IFN- $\gamma$. The role of IFN- $\gamma$, the central cytokine in primary HLH, has been challenged in secondary HLH by several findings. In the IL6-transgenic mouse model, neutralization of IFN- $\gamma$ effectively improved survival and clinical parameters (Prencipe et al, 2015), while in a novel virus-associated secondary HLH model, IFN- $\gamma$-deficient mice displayed an exacerbated phenotype (Brisse et al, 2016). In the TLR9-triggered mouse model, the impact of IFN- $\gamma$ was conditional to the disease-modulating effect of IL10. During IL10-receptor blockade, when most severe MAS was observed, only the development of anaemia was IFN- $\gamma$-restricted. Characteristic HLH symptoms like haemophagocytosis, hyperferritinaemia, hepatitis, splenomegaly and thrombocytopenia still developed in the absence of IFN- $\gamma$ (Behrens et al, 2011; Canna et al, 2013; Brisse et al, 2016). Thus, cytokines other than IFN- $\gamma$ can drive disease in secondary HLH. Probably multiple mechanisms, adaptive or innate, can underlie HLH pathogenesis.

\section{A blurring distinction between primary and secondary HLH}

Traditionally, primary HLH was defined by the presence of homozygous mutations in cytotoxicity-related genes. Conversely, secondary HLH was classically determined to have no genetic background. Evidence is currently accumulating for genetic overlap between both. In some patients with classical 'secondary' HLH, monoallelic mutations or polymorphisms have been detected in genes typically implicated in primary HLH (Table II) (Kaufman et al, 2014; Wang et al, 2014; Zhang et al, 2014a,b). Some of these polymorphisms are relatively frequent in the general population (up to $9 \%$ minor allele frequency for PRF1 A91V), while several base changes, present in non-conserved gene regions, are predicted in silico to be benign. Therefore it remains uncertain how they relate to HLH pathogenesis. Presumably they are not clinically neutral given their enrichment in patients with secondary HLH compared to healthy or inflammatory controls (Zhang et al, 2008a; Vastert et al, 2010; Kaufman et al, 2014). Only one study reported no enrichment of monoallelic rare variants in secondary HLH, compared to a large healthy control cohort (Tesi et al, 2015b). Theoretically, hypomorphic single-copy mutations may alter protein levels and thus induce subtle impairment of cytotoxicity, increasing susceptibility to infections. Interestingly, heterozygous mutations in PRF1 and LYST have also been implicated in severe H1N1 influenza (Schulert et al, 2016), suggesting the sequence variants are not strictly recessive but may generate haploinsufficiency for cytotoxicity genes (Zhang et al, 2011, 2014a,b; Tesi et al, 2015b; Cetica et al, 2016).

The discovery of heterozygous defects in secondary HLH has reduced its distinction with late-onset/atypical primary HLH to a matter of semantics. Both subtypes comprise heterozygous monogenic, bigenic or polygenic subgroups (Kaufman et al, 2014; de Saint Basile et al, 2015).
Table II. Genetic factors in secondary haemophagocytic lymphohistiocytosis

Polymorphisms contributing to secondary haemophagocytic

lymphohistiocytosis susceptibility

Granule-mediated cytotoxicity

PRF1, UNC13D, STX11, STXBP2, RAB27A, SH2D1A, LYST

Microtubule organization

CCDC141, XIRP2, ARHGAP21, MICAL2

Vesicle transport

FAM160A2, EXPH5, CADPS2, FKBPL, GDI1

NK cell receptors

KIR2DS5, KIR3DS1

Cytokine production and signalling

IL10, TGFB, IFNGR1, IFNGR2, NLRC4, IRF5

Inflammasome activation

NLRC4

TLR signalling

IRF5

Primary immunodeficiency genes

IL2RG, RAG1, CD127, CD3E, GATA2, CD27, ITK, MAGT1, BTK,

FAS, NLRP3, MEFV, TNFRSF1A, IKBKG, STAT1, WAS, ATM,

CYBB, 22q11.2 deletion

Function unknown

LRGUK

NK, natural killer; TLR, Toll-like receptor.

Nonetheless, patients carrying typical primary HLH-linked mutations or polymorphisms account for only a minor percentage of secondary HLH, approximately $7-18 \%$ in the largest cohorts (Zhang et al, 2011, 2014a; Wang et al, 2014; Cetica et al, 2016), signifying the existence of other predisposing factors in the majority of secondary HLH patients.

Extensive whole-exome sequencing in secondary HLH patients has revealed homozygous, compound heterozygous and heterozygous protein-altering mutations in non-primary HLH-related genes as well. Some of these genes were indirectly involved in the cytolytic pathway, e.g. encoding regulators of actin and microtubule reorganization or vesiclemediated transport (Table II). As mutations in these genes were enriched in secondary HLH patients, they also deserve attention as new gene candidates in primary HLH (Kaufman et al, 2014).

Mutations and polymorphisms in non-cytotoxicity-related genes, affecting NK cell receptors, cytokine production, cytokine signalling, inflammasome activation and TLR signalling, may also predispose to secondary HLH (Table II). Polymorphisms in activating killer cell immunoglobulin-like receptors or in IL10 and TGFB constitute risk factors for EBV-associated HLH (Hatta et al, 2007; Qiang et al, 2012; Wang et al, 2015). Noteworthy, IL10 fulfils a protective function in HLH animal models (reviewed in Brisse et al, 2015) and IL10 polymorphisms associated with low IL10 production are enriched in sJIA patients, which might relate to their susceptibility to HLH (Fife et al, 2006). Recently, the first report appeared of two IFN- $\gamma$-receptor-deficient patients who 

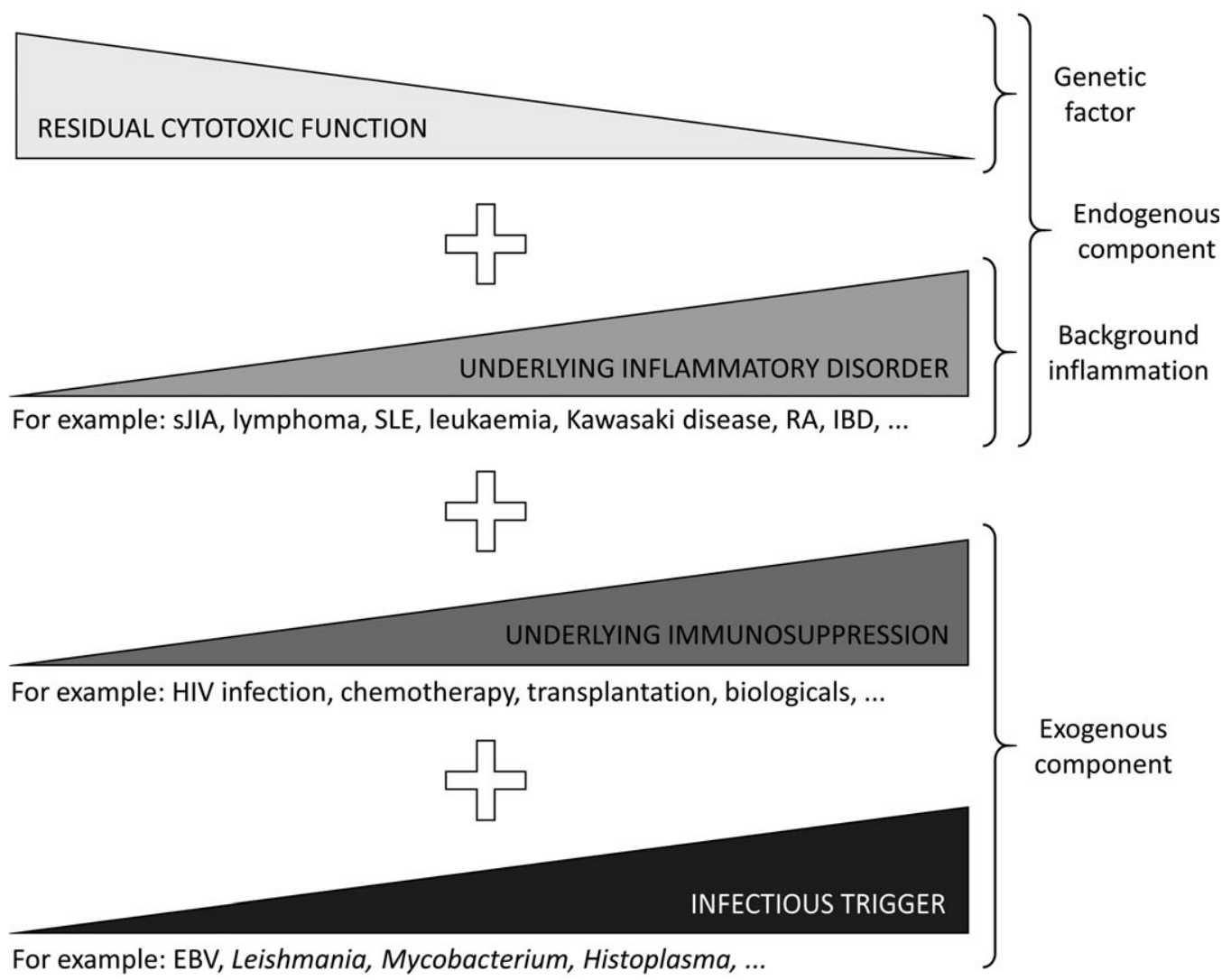

For example: EBV, Leishmania, Mycobacterium, Histoplasma, ...
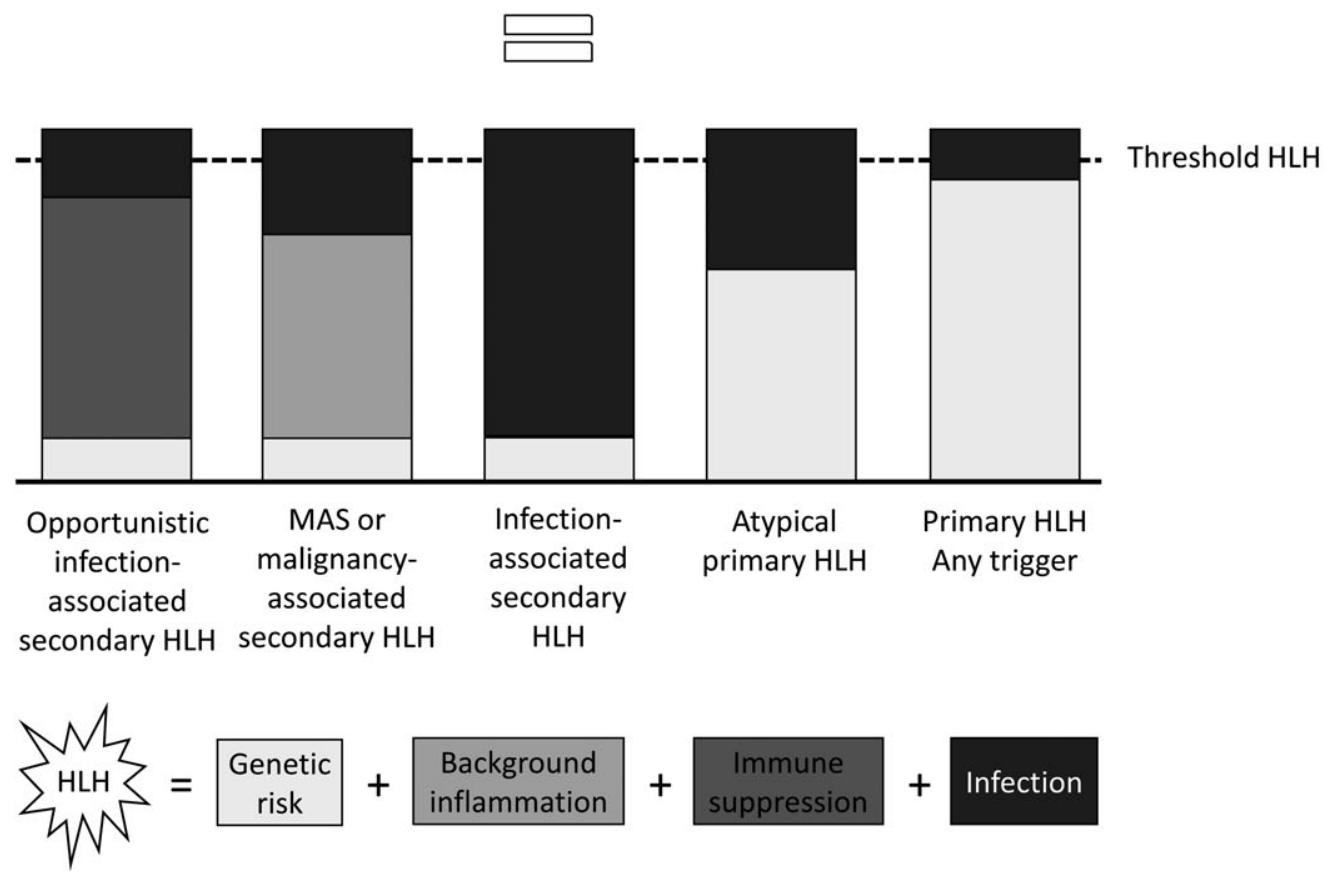

Fig 3. Threshold model of the HLH spectrum. Genetic factors (as explained in Fig 1), background inflammation (as contributed by underlying immune disorders and/or malignancies), underlying immunosuppression and different strengths of infectious triggers are superimposed until a certain threshold point is reached, beyond which inflammation is no longer controlled and fulminant HLH develops. Diverse pathways and aetiologies can thus result in the same common end stage of HLH. EBV, Epstein-Barr virus; HIV, human immunodeficiency virus; HLH, haemophagocytic lymphohistiocytosis; IBD, inflammatory bowel disease; MAS, macrophage activation syndrome; RA, rheumatoid arthritis; sJIA, systemic juvenile idiopathic arthritis; SLE, systemic lupus erythematosus. 
acquired HLH in the absence of functional IFN- $\gamma$-signalling, constituting formal proof that HLH can emerge independent of IFN- $\gamma$, not only in animal models (Canna et al, 2013), but also in humans (Tesi et al, 2015c). Secondary HLH patients carrying heterozygous NLRC4 mutations have also been described (Canna \& Goldbach-Mansky, 2015). Lastly, activating polymorphisms in IRF5, a TLR-signalling molecule and master transcription factor for pro-inflammatory cytokines, were associated with susceptibility to secondary HLH (Yanagimachi et al, 2011a,b).

Furthermore, HLH can complicate various monogenic disorders. Categorizing these cases as primary or secondary HLH is challenging, as the extent to which the underlying mutations contribute to HLH is unknown (Table II). HLH occurs most frequently in primary immunodeficient (PID) patients with severe $\mathrm{T}$ or NK cell deficiencies, for instance due to $I L 2 R G$ or $R A G-1$ mutations. In these patients, who are profoundly lymphopenic, HLH seems to develop independently of $\mathrm{T}$ or $\mathrm{NK}$ cells and is generally linked to impaired viral control (Faitelson \& Grunebaum, 2014; Bode et al, 2015). Patients carrying CD27, ITK or MAGT1 mutations show increased susceptibility to EBV-induced HLH. Arguably, these cases could be classified as primary HLH, analogous to XLP (Lehmberg et al, 2015a). HLH in myeloid PIDs, such as chronic granulomatous disease, is less frequent and mostly associated with bacterial infections (Faitelson \& Grunebaum, 2014; Bode et al, 2015). Rarely, other monogenic autoinflammatory disorders are complicated by HLH, including familial Mediterranean fever and cryoperin-associated periodic syndrome (Rigante et al, 2015), which involve spontaneous inflammasome activation, similar to NLRC4-associated HLH (Canna \& GoldbachMansky, 2015).

Thus, although formerly only primary HLH was thought to involve genetic factors, some degree of genetic predisposition may also be implicated in secondary HLH.

\section{Conclusion: HLH as a threshold disease}

Based on the presented arguments, HLH can no longer be considered a binary disorder, divided into 'genetic' or 'acquired' forms. HLH rather represents a continuum in which diverse aetiologies and pathogenic mechanisms result in the same endpoint of a fulminant haemophagocytic syndrome. In this regard, HLH can be portrayed as a 'threshold' disease (Fig 3). The weight of different predisposing factors is combined until a threshold is exceeded, above which inflammation is no longer controlled. Endogenous components, such as genetic factors, determine the residual cytotoxic function of patients, while underlying disorders contribute to background inflammation. Concomitant immunosuppression may cause further imbalance in immune homeostasis and influence host susceptibility to exogenous triggers, including infections of variable severity. By combined action of these diverse factors, a wide spectrum of HLH can develop, ranging from typical FHL to infection-associated secondary HLH (Strippoli et al, 2013; de Saint Basile et al, 2015; Cetica et al, 2016).

\section{Acknowledgements}

This work was supported by the Agency for Innovation by Science and Technology (IWT), Flanders' Regional Government (GOA programme) and the Interuniversity Attraction Poles (IAP). E.B. received an IWT fellowship. We thank Professor Billiau for critically reviewing the manuscript. The authors declare no conflicting interests.

\section{Author contributions}

E.B. has written the review article. C.H.W. and P.M. have thoroughly and critically revised the manuscript.

\section{References}

Atteritano, M., David, A., Bagnato, G., Beninati, C., Frisina, A., Iaria, C. \& Cascio, A. (2012) Haemophagocytic syndrome in rheumatic patients. A systematic review. European Review for Medical and Pharmacological Sciences, 16, 1414-24.

Avau, A., Put, K., Wouters, C.H. \& Matthys, P. (2015) Cytokine balance and cytokine-driven natural killer cell dysfunction in systemic juvenile idiopathic arthritis. Cytokine \& Growth Factor Reviews, 26, 35-45.

Behrens, E.M., Canna, S.W., Slade, K., Rao, S., Kreiger, P.A., Paessler, M., Kambayashi, T. \& Koretzky, G.A. (2011) Repeated TLR9 stimulation results in macrophage activation syndrome - like disease in mice. The Journal of Clinical Investigation, 121, 2264-2277.

Billiau, A.D., Roskams, T., Van Damme-Lombaerts, R., Matthys, P. \& Wouters, C. (2005)
Macrophage activation syndrome: characteristic findings on liver biopsy illustrating the key role of activated, IFN-gamma-producing lymphocytes and IL-6- and TNF-alpha-producing macrophages. Blood, 105, 1648-51.

Bode, S.F.N., Ammann, S., Al-Herz, W., Bataneant, M., Dvorak, C.C., Gehring, S., Gennery, A., Gilmour, K.C., Gonzalez-Granado, L.I., GroBWieltsch, U., Ifversen, M., Lingman-Framme, J., Matthes-Martin, S., Mesters, R., Meyts, I., van Montfrans, J.M., Pachlopnik Schmid, J., Pai, S.Y., Soler-Palacin, P., Schuermann, U., Schuster, V., Seidel, M.G., Speckmann, C., Stepensky, P., Sykora, K.-W., Tesi, B., Vraetz, T., Waruiru, C., Bryceson, Y.T., Moshous, D., Lehmberg, K., Jordan, M.B. \& Ehl, S. (2015) The syndrome of hemophagocytic lymphohistiocytosis in primary immunodeficiencies: implications for differential diagnosis and pathogenesis. Haematologica, 100, 978-988.
Brisse, E., Wouters, C.H. \& Matthys, P. (2015) Hemophagocytic lymphohistiocytosis (HLH): a heterogeneous spectrum of cytokine-driven immune disorders. Cytokine \& Growth Factor Reviews, 26, 263-280.

Brisse, E., Imbrechts, M., Put, K., Avau, A., Mitera, T., Berghmans, N., Rutgeerts, O., Waer, M., Ninivaggi, M., Kelchtermans, H., Boon, L., Snoeck, R., Andrei, G. \& Matthys, P. (2016) Mouse cytomegalovirus infection in $\mathrm{BALB} / \mathrm{c}$ mice resembles virus-associated secondary hemophagocytic lymphohistiocytosis and shows a pathogenesis distinct from primary hemophagocytic lymphohistiocytosis. The Journal of Immunology, 196, 3124-3134.

Bryceson, Y.T., Pende, D., Maul-Pavicic, A., Gilmour, K.C., Ufheil, H., Vraetz, T., Chiang, S.C., Marcenaro, S., Meazza, R., Bondzio, I., Walshe, D., Janka, G., Lehmberg, K., Beutel, K., zur Stadt, U., Binder, N., Arico, M., Moretta, L., 
Henter, J.I. \& Ehl, S. (2012) A prospective evaluation of degranulation assays in the rapid diagnosis of familial hemophagocytic syndromes. Blood, 119, 2754-2763.

Canna, S.W. \& Goldbach-Mansky, R. (2015) New monogenetic autoinflammatory diseases - a clinical overview. Seminars in Immunopathology, 37, 387-394.

Canna, S.W., Wrobel, J., Chu, N., Kreiger, P.A., Paessler, M. \& Behrens, E.M. (2013) Interferon- $\gamma$ mediates anemia but is dispensable for fulminant toll-like receptor 9-induced macrophage activation syndrome and hemophagocytosis in mice. Arthritis and Rheumatism, 65, 1764-75.

Cetica, V., Sieni, E., Pende, D., Danesino, C., De Fusco, C., Locatelli, F., Micalizzi, C., Putti, M.C., Biondi, A., Fagioli, F., Moretta, L., Griffiths, G.M., Luzzatto, L. \& Aricò, M. (2016) Genetic predisposition to hemophagocytic lymphohistiocytosis: report on 500 patients from the Italian registry. The Journal of Allergy and Clinical Immunology, 137, 188-196.

Chuang, H.-C., Lay, J.-D., Hsieh, W.-C., Wang, H.-C., Chang, Y., Chuang, S.-E. \& Su, I.-J. (2005) Epstein-Barr virus LMP1 inhibits the expression of SAP gene and upregulates Th1 cytokines in the pathogenesis of hemophagocytic syndrome. Blood, 106, 3090-6.

Cifaldi, L., Prencipe, G., Caiello, I., Bracaglia, C., Locatelli, F., De Benedetti, F. \& Strippoli, R. (2015) Inhibition of natural killer cell cytotoxicity by interleukin-6: implications for the pathogenesis of macrophage activation syndrome. Arthritis \& Rheumatology, 67, 3037-46.

Cron, R.Q., Behrens, E.M., Shakoory, B., Ramanan, A.V. \& Chatham, W.W. (2015) Does viral hemorrhagic fever represent reactive hemophagocytic syndrome? The Journal of Rheumatology, 42, 1078-1080.

D’Orlando, O., Zhao, F., Kasper, B., Orinska, Z., Müller, J., Hermans-Borgmeyer, I., Griffiths, G.M., Zur Stadt, U. \& Bulfone-Paus, S. (2013) Syntaxin 11 is required for NK and $\mathrm{CD} 8^{+} \mathrm{T}$-cell cytotoxicity and neutrophil degranulation. European Journal of Immunology, 43, 194-208.

Dotta, L., Parolini, S., Prandini, A., Tabellini, G., Antolini, M., Kingsmore, S.F. \& Badolato, R. (2013) Clinical, laboratory and molecular signs of immunodeficiency in patients with partial oculo-cutaneous albinism. Orphanet Journal of Rare Diseases, 8, 168-177.

Enders, A., Zieger, B., Schwarz, K., Yoshimi, A., Speckmann, C., Knoepfle, E.-M., Kontny, U., Müller, C., Nurden, A., Rohr, J., Henschen, M., Pannicke, U., Niemeyer, C., Nurden, P. \& Ehl, S. (2006) Lethal hemophagocytic lymphohistiocytosis in Hermansky-Pudlak syndrome type II. Blood, 108, 81-7.

Entesarian, M., Chiang, S.C.C., Schlums, H., Meeths, M., Chan, M.-Y., Mya, S.-N., Soh, S.-Y., Nordenskjöld, M., Henter, J.-I. \& Bryceson, Y.T. (2013) Novel deep intronic and missense UNC13D mutations in familial haemophagocytic lymphohistiocytosis type 3 . British Journal of Haematology, 162, 415-8.

Faitelson, Y. \& Grunebaum, E. (2014) Hemophagocytic lymphohistiocytosis and primary immune deficiency disorders. Clinical Immunology, 155, 118-125.

Fife, M.S., Gutierrez, A., Ogilvie, E.M., Stock, C.J.W., Samuel, J.M., Thomson, W., Mack, L.F., Lewis, C.M. \& Woo, P. (2006) Novel IL10 gene family associations with systemic juvenile idiopathic arthritis. Arthritis Research \& Therapy, 8, R148.

Gao, L., Dang, X., Huang, L., Zhu, L., Fang, M., Zhang, J., Xu, X., Zhu, L., Li, T., Zhao, L., Wei, J. \& Zhou, J. (2016) Search for the potential 'second-hit' mechanism underlying the onset of familial hemophagocytic lymphohistiocytosis type 2 by whole-exome sequencing analysis. Translational Research, 170, 26-39.

George, M.R. (2014) Hemophagocytic lymphohistiocytosis: review of etiologies and management. Journal of Blood Medicine, 5, 69-86.

Grom, A.A. (2004) Natural killer cell dysfunction: a common pathway in systemic-onset juvenile rheumatoid arthritis, macrophage activation syndrome, and hemophagocytic lymphohistiocytosis? Arthritis and Rheumatism, 50, 689-98.

Grom, A., Villanueva, J., Lee, S., Goldmuntz, E., Passo, M. \& Filipovich, A.H. (2003) Natural killer cell dysfunction in patients with systemiconset rheumatoid arthritis and macrophage activation syndrome. Journal of Pediatrics, 29, 2296.

Hackmann, Y., Graham, S.C., Ehl, S., Honing, S., Lehmberg, K., Arico, M., Owen, D.J. \& Griffiths, G.M. (2013) Syntaxin binding mechanism and disease-causing mutations in Munc18-2. Proceedings of the National Academy of Sciences of the United States of America, 110, E4482E4491.

Hatta, K., Morimoto, A., Ishii, E., Kimura, H., Ueda, I., Hibi, S., Todo, S., Sugimoto, T. \& Imashuku, S. (2007) Association of transforming growth factor-betal gene polymorphism in the development of Epstein-Barr virus-related hematologic diseases. Haematologica, 92, 1470-4.

Henter, J.I., Elinder, G., Söder, O., Hansson, M., Andersson, B. \& Andersson, U. (1991) Hypercytokinemia in familial hemophagocytic lymphohistiocytosis. Blood, 78, 2918-2922.

Holle, J.R., Marsh, R.A., Holdcroft, A.M., Davies, S.M., Wang, L., Zhang, K. \& Jordan, M.B. (2015) Hemophagocytic lymphohistiocytosis in a female patient due to a heterozygous XIAP mutation and skewed X chromosome inactivation. Pediatric Blood \& Cancer, 62, 1288-1290.

Horne, A., Ramme, K.G., Rudd, E., Zheng, C., Wali, Y., Al-Lamki, Z., Gürgey, A., Yalman, N., Nordenskjöld, M. \& Henter, J.I. (2008) Characterization of PRF1, STX11 and UNC13D genotype-phenotype correlations in familial hemophagocytic lymphohistiocytosis. British Journal of Haematology, 143, 75-83.

Hsieh, S. \& Chang, S. (2006) Cutting edge: insufficient perforin expression in CD8+ $\mathrm{T}$ cells in response to hemagglutinin from avian influenza (H5N1) virus. The Journal of Immunology, 176, 4530-4533.

Humblet-Baron, S., Franckaert, D., Dooley, J., Bornschein, S., Cauwe, B., Schönefeldt, S., Bossuyt, X., Matthys, P., Baron, F., Wouters, C. \& Liston, A. (2016) IL-2 consumption by highly activated CD8 $\mathrm{T}$ cells induces regulatory $\mathrm{T}$-cell dysfunction in patients with hemophagocytic lymphohistiocytosis. The Journal of Allergy and Clinical Immunology. doi:10.1016/j.jaci.2015. 12.1314

Janka, G.E. \& Lehmberg, K. (2014) Hemophagocytic syndromes - An update. Blood Reviews, 28, 135-142.

Jenkins, M.R., Rudd-Schmidt, J.A., Lopez, J.A., Ramsbottom, K.M., Mannering, S.I., Andrews, D.M., Voskoboinik, I. \& Trapani, J.A. (2015) Failed CTL/NK cell killing and cytokine hypersecretion are directly linked through prolonged synapse time. Journal of Experimental Medicine, 212, 307-317.

Jerome, K.R., Tait, J.F., Koelle, D.M. \& Corey, L. (1998) Herpes simplex virus type 1 renders infected cells resistant to cytotoxic T-lymphocyte-induced apoptosis. Journal of Virology, 72, 436-41.

Jessen, B., Maul-Pavicic, A., Ufheil, H., Vraetz, T., Enders, A., Lehmberg, K., Längler, A., GrossWieltsch, U., Bay, A., Kaya, Z., Bryceson, Y.T., Koscielniak, E., Badawy, S., Davies, G., Hufnagel, M., Schmitt-Graeff, A., Aichele, P., Zur Stadt, U., Schwarz, K. \& Ehl, S. (2011) Subtle differences in CTL cytotoxicity determine susceptibility to hemophagocytic lymphohistiocytosis in mice and humans with Chediak-Higashi syndrome. Blood, 118, 4620-9.

Jessen, B., Bode, S.F., Ammann, S., Chakravorty, S., Davies, G., Diestelhorst, J., Frei-Jones, M., Gahl, W.A., Gochuico, B.R., Griese, M., Griffiths, G., Janka, G., Klein, C., Kogl, T., Kurnik, K., Lehmberg, K., Maul-Pavicic, A., Mumford, A.D., Pace, D., Parvaneh, N., Rezaei, N., de Saint Basile, G., Schmitt-Graeff, A., Schwarz, K., Karasu, G.T., Zieger, B., Zur Stadt, U., Aichele, P. \& Ehl, S. (2013a) The risk of hemophagocytic lymphohistiocytosis in Hermansky-Pudlak syndrome type 2. Blood, 121, 2943-2951.

Jessen, B., Kögl, T., Sepulveda, F.E., de Saint Basile, G., Aichele, P. \& Ehl, S. (2013b) Graded defects in cytotoxicity determine severity of hemophagocytic lymphohistiocytosis in humans and mice. Frontiers in Immunology, 4, e448.

Jordan, M.B., Hildeman, D., Kappler, J. \& Marrack, P. (2004) An animal model of hemophagocytic lymphohistiocytosis (HLH): CD8 $+\mathrm{T}$ cells and interferon gamma are essential for the disorder. Blood, 104, 735-743.

Kasahara, Y., Yachie, A., Takei, K., Kanegane, C., Okada, K., Ohta, K., Seki, H., Igarashi, N., Maruhashi, K., Katayama, K., Katoh, E., Terao, G., Sakiyama, Y. \& Koizumi, S. (2001) Differential cellular targets of Epstein-Barr virus (EBV) infection between acute EBV-associated 
hemophagocytic lymphohistiocytosis and chronic active EBV infection. Blood, 98, 18821888.

Kaufman, K.M., Linghu, B., Szustakowski, J.D., Husami, A., Yang, F., Zhang, K., Filipovich, A., Fall, N., Harley, J.B., Nirmala, N.R. \& Grom, A.A. (2014) Whole exome sequencing reveals overlap between macrophage activation syndrome in systemic juvenile idiopathic arthritis and familial hemophagocytic lymphohistiocytosis. Arthritis \& Rheumatism, 66, 3486-3495.

Kögl, T., Müller, J., Jessen, B., Schmitt-graeff, A., Janka, G., Ehl, S., zur Stadt, U., Aichele, P. \& Ko, T. (2013) Hemophagocytic lymphohistiocytosis in syntaxin-11-deficient mice: T-cell exhaustion limits fatal disease. Blood, 121, 604613.

Kostova, E.B., Beuger, B.M., Veldthuis, M., van der Werff ten Bosch, J., Kühnle, I., van den Akker, E., van den Berg, T.K., van Zwieten, R. \& van Bruggen, R. (2015) Intrinsic defects in erythroid cells from familial hemophagocytic lymphohistiocytosis type 5 patients identify a role for STXBP2/Munc18-2 in erythropoiesis and phospholipid scrambling. Experimental Hematology, 43, 1072-1076.

Krebs, P., Crozat, K., Popkin, D., Oldstone, M.B. \& Beutler, B. (2011) Disruption of MyD88 signaling suppresses hemophagocytic lymphohistiocytosis in mice. Blood, 117, 6582-8.

Lehmberg, K., Nichols, K.E., Henter, J.-I., Girschikofsky, M., Greenwood, T., Jordan, M., Kumar, A., Minkov, M., La Rosée, P. \& Weitzman, S.; Study Group on Hemophagocytic Lymphohistiocytosis Subtypes of the Histiocyte Society (2015a) Consensus recommendations for the diagnosis and management of hemophagocytic lymphohistiocytosis associated with malignancies. Haematologica, 100, 9971004.

Lehmberg, K., Sprekels, B., Nichols, K.E., Woessmann, W., Müller, I., Suttorp, M., Bernig, T., Beutel, K., Bode, S.F.N., Kentouche, K., Kolb, R., Längler, A., Minkov, M., Schilling, F.H., Schmid, I., Vieth, S., Ehl, S., Zur Stadt, U. \& Janka, G.E. (2015b) Malignancy-associated haemophagocytic lymphohistiocytosis in children and adolescents. British Journal of Haematology, 170, 539-549.

Löfstedt, A., Chiang, S.C.C., Onelöv, E., Bryceson, Y.T., Meeths, M. \& Henter, J.-I. (2015) Cancer risk in relatives of patients with a primary disorder of lymphocyte cytotoxicity: a retrospective cohort study. The Lancet. Haematology, 2, e53642.

Lykens, J.E., Terrell, C.E., Zoller, E.E., Risma, K. \& Jordan, M.B. (2011) Perforin is a critical physiologic regulator of T-cell activation. Blood, 118, 618-26.

Mao, H., Tu, W., Qin, G., Law, H.K.W., Sia, S.F., Chan, P.-L., Liu, Y., Lam, K.-T., Zheng, J., Peiris, M. \& Lau, Y.-L. (2009) Influenza virus directly infects human natural killer cells and induces cell apoptosis. Journal of Virology, 83, 9215-22.
Marsh, R.a., Madden, L., Kitchen, B.J., Mody, R., McClimon, B., Jordan, M.B., Bleesing, J.J., Zhang, K. \& Filipovich, A.H. (2010) XIAP deficiency: a unique primary immunodeficiency best classified as X-linked familial hemophagocytic lymphohistiocytosis and not as X-linked lymphoproliferative disease. Blood, 116, 1079-82.

Meeths, M., Chiang, S.C.C., Löfstedt, A., Müller, M.L., Tesi, B., Henter, J.I. \& Bryceson, Y.T. (2014) Pathophysiology and spectrum of diseases caused by defects in lymphocyte cytotoxicity. Experimental Cell Research, 325, 10-17.

Nagasawa, M., Yi, Z., Imashuku, S., Nonoyama, S., Ogawa, K., Okumura, K. \& Mizutani, S. (2008) Soluble TWEAK is markedly elevated in hemophagocytic lymphohistiocytosis. American Journal of Hematology, 83, 222-5.

Nakamura, L., Bertling, A., Brodde, M.F., Zur Stadt, U., Schulz, A.S., Ammann, S., SandrockLang, K., Beutel, K., Zieger, B. \& Kehrel, B.E. (2015) First characterization of platelet secretion defect in patients with familial hemophagocytic lymphohistiocytosis type 3 (FHL-3). Blood, 125, $412-4$

Ohadi, M., Lalloz, M.R., Sham, P., Zhao, J., Dearlove, A.M., Shiach, C., Kinsey, S., Rhodes, M. \& Layton, D.M. (1999) Localization of a gene for familial hemophagocytic lymphohistiocytosis at chromosome 9q21.3-22 by homozygosity mapping. American Journal of Human Genetics, 64, $165-71$.

Ohyagi, H., Onai, N., Sato, T., Yotsumoto, S., Liu, J., Akiba, H., Yagita, H., Atarashi, K., Honda, K., Roers, A., Müller, W., Kurabayashi, K., Hosoi-Amaike, M., Takahashi, N., Hirokawa, M., Matsushima, K., Sawada, K. \& Ohteki, T. (2013) Monocyte-derived dendritic cells perform hemophagocytosis to fine-tune excessive immune responses. Immunity, 39, 584-98.

Osugi, Y., Hara, J., Tagawa, S., Takai, K., Hosoi, G., Matsuda, Y., Ohta, H., Fujisaki, H., Kobayashi, M., Sakata, N., Kawa-Ha, K., Okada, S. \& Tawa, A. (1997) Cytokine production regulating Th1 and Th2 cytokines in hemophagocytic lymphohistiocytosis. Blood, 89, 4100-3.

Pachlopnik Schmid, J., Ho, C.-H., Chrétien, F., Lefebvre, J.M., Pivert, G., Kosco-Vilbois, M., Ferlin, W., Geissmann, F., Fischer, A. \& de Saint Basile, G. (2009) Neutralization of IFNgamma defeats haemophagocytosis in LCMV-infected perforin- and Rab27a-deficient mice. EMBO Molecular Medicine, 1, 112-24.

Pagel, J., Beutel, K., Lehmberg, K., Koch, F., MaulPavicic, A., Rohlfs, A.-K., Al-Jefri, A., Beier, R., Bomme Ousager, L., Ehlert, K., Gross-Wieltsch, U., Jorch, N., Kremens, B., Pekrun, A., SparberSauer, M., Mejstrikova, E., Wawer, A., Ehl, S., zur Stadt, U. \& Janka, G. (2012) Distinct mutations in STXBP2 are associated with variable clinical presentations in patients with familial hemophagocytic lymphohistiocytosis type 5 (FHL5). Blood, 119, 6016-24.

Palendira, U., Low, C., Chan, A., Hislop, A.D., Ho, E., Phan, T.G., Deenick, E., Cook, M.C., Riminton, D.S., Choo, S., Loh, R., Alvaro, F.,
Booth, C., Gaspar, H.B., Moretta, A., Khanna, R., Rickinson, A.B. \& Tangye, S.G. (2011) Molecular pathogenesis of EBV susceptibility in XLP as revealed by analysis of female carriers with heterozygous expression of SAP. PLoS Biology, 9, e1001187.

Palmblad, K., Schierbeck, H., Sundberg, E., Horne, A.-C., Harris, H.E., Henter, J.-I., Antoine, D.J. \& Andersson, U. (2014) High systemic levels of the cytokine-inducing HMGB1 isoform secreted in severe macrophage activation syndrome. Molecular Medicine, 20, 538-47.

Prencipe, G., Caiello, I., Bracaglia, C., de Min, C. \& De Benedetti, F. (2015) Neutralization of Interferon-gamma is efficacious in a mouse model of HLH secondary to chronic inflammation. Pediatric Rheumatology, 13, O29.

Put, K., Avau, A., Brisse, E., Mitera, T., Put, S., Proost, P., Bader-Meunier, B., Westhovens, R., Van den Eynde, B.J., Orabona, C., Fallarino, F. De Somer, L., Tousseyn, T., Quartier, P., Wouters, C. \& Matthys, P. (2015) Cytokines in systemic juvenile idiopathic arthritis and haemophagocytic lymphohistiocytosis: tipping the balance between interleukin-18 and interferon- $\gamma$. Rheumatology, 54, 1507-1517.

Qian, Y., Johnson, J.A., Connor, J.A., Valencia, A. Barasa, N., Schubert, J., Husami, A., Kissell, D., Zhang, G., Weirauch, M.T., Filipovich, A.H. \& Zhang, K. (2014) The 253-kb inversion and deep intronic mutations in UNC13D are present in North American patients with familial hemophagocytic lymphohistiocytosis 3. Pediatric Blood \& Cancer, 61, 1034-1040.

Qiang, Q., Zhengde, X., Chunyan, L., Zhizhuo, H. Junmei, X., Junhong, A., Zheng, C., Henter, J.-I \& Kunling, S. (2012) Killer cell immunoglobulin-like receptor gene polymorphisms predispose susceptibility to Epstein-Barr virus associated hemophagocytic lymphohistiocytosis in Chinese children. Microbiology and Immunology, 56, 37884.

Ramanan, A.V. \& Schneider, R. (2003) Macrophage activation syndrome-what's in a name! The Journal of Rheumatology, 30, 2513-6.

Ramos-Casals, M., Brito-Zerón, P., López-Guillermo, A., Khamashta, M.A. \& Bosch, X. (2014) Adult haemophagocytic syndrome. Lancet, 383, 1503-16.

Rigante, D., Emmi, G., Fastiggi, M., Silvestri, E. \& Cantarini, L. (2015) Macrophage activation syndrome in the course of monogenic autoinflammatory disorders. Clinical Rheumatology, 34, 1333-1339.

Rood, J.E., Rao, S., Paessler, M., Kreiger, P.A., Chu, N., Stelekati, E., Wherry, E.J. \& Behrens, E.M. (2016) ST2 contributes to T cell hyperactivation and fatal hemophagocytic lymphohistiocytosis in mice. Blood, 127, 426-435.

Rouphael, N.G., Talati, N.J., Vaughan, C., Cunningham, K., Moreira, R. \& Gould, C. (2007) Infections associated with haemophagocytic syndrome. The Lancet. Infectious diseases, 7, 814-822.

de Saint Basile, G., Sepulveda, F.E., Maschalidi, S. \& Fischer, A. (2015) Cytotoxic granule secretion 
by lymphocytes and its link to immune homeostasis. F1000Research, 4, 930-938.

Schulert, G.S., Zhang, M., Fall, N., Husami, A., Kissell, D., Hanosh, A., Zhang, K., Davis, K., Jentzen, J.M., Napolitano, L., Siddiqui, J., Smith, L.B., Harms, P.W., Grom, A.A. \& Cron, R.Q. (2016) Whole exome sequencing reveals mutations in hemophagocytic lymphohistiocytosis and macrophage activation syndrome linked genes in fatal cases of H1N1 influenza. The Journal of Infectious Diseases, 213, 1180-1188.

Sepulveda, F.E., Debeurme, F., Ménasché, G., Kurowska, M., Côte, M., Pachlopnik Schmid, J., Fischer, A. \& de Saint Basile, G. (2013) Distinct severity of HLH in both human and murine mutants with complete loss of cytotoxic effector PRF1, RAB27A, and STX11. Blood, 121, 595603.

Sepulveda, F.E., Maschalidi, S., Vosshenrich, C.A.J., Garrigue, A., Kurowska, M., Ménasche, G., Fischer, A., Di Santo, J.P. \& de Saint Basile, G. (2015) A novel immunoregulatory role for NK-cell cytotoxicity in protection from HLHlike immunopathology in mice. Blood, 125, 1427-34.

Sepulveda, F.E., Garrigue, A., Maschalidi, S., Garfa-Traore, M., Ménasché, G., Fischer, A. \& de Saint Basile, G. (2016) Polygenic mutations in the cytotoxicity pathway increase susceptibility to develop HLH immunopathology in mice. Blood. doi:10.1182/blood-2015-12-688960

Sieni, E., Cetica, V., Hackmann, Y., Coniglio, M.L., Da Ros, M., Ciambotti, B., Pende, D., Griffiths, G. \& Aricò, M. (2014) Familial hemophagocytic lymphohistiocytosis: when rare diseases shed light on immune system functioning. Frontiers in Immunology, 5, 1-19.

Spessott, W.A., Sanmillan, M.L., McCormick, M.E., Patel, N., Villanueva, J., Zhang, K., Nichols, K.E. \& Giraudo, C.G. (2015) Hemophagocytic lymphohistiocytosis caused by dominant-negative mutations in STXBP2 that inhibit SNARE-mediated membrane fusion. Blood, 125, 1566-77.

Stepensky, P., Bartram, J., Barth, T.F., Lehmberg, K., Walther, P., Amann, K., Philips, A.D., Beringer, O., Zur Stadt, U., Schulz, A., Amrolia, P., Weintraub, M., Debatin, K., Hoenig, M. \& Posovszky, C. (2013) Persistent Defective Membrane Trafficking in Epithelial Cells of Patients With Familial Hemophagocytic Lymphohistiocytosis Type 5 Due to STXBP2/MUNC18-2 Mutations. Pediatric Blood \& Cancer, 60, 1215-22.

Stepp, S.E., Dufourcq-Lagelouse, R., Le Deist, F., Bhawan, S., Certain, S., Mathew, P.A., Henter, J.I., Bennett, M., Fischer, A., de Saint Basile, G. \& Kumar, V. (1999) Perforin gene defects in familial hemophagocytic lymphohistiocytosis. Science, 286, 1957-9.

Strippoli, R., Carvello, F., Scianaro, R., De Pasquale, L., Vivarelli, M., Petrini, S., Bracci-Laudiero, L. \& De Benedetti, F. (2012) Amplification of the response to Toll-like receptor ligands by prolonged exposure to interleukin-6 in mice: implication for the pathogenesis of macrophage activation syndrome. Arthritis and Rheumatism, 64, 1680-8.

Strippoli, R., Caiello, I. \& De Benedetti, F. (2013) Reaching the threshold: a multilayer pathogenesis of macrophage activation syndrome. The Journal of Rheumatology, 40, 761-7.

Sumegi, J., Barnes, M.G., Nestheide, S.V., MolleranLee, S., Villanueva, J., Zhang, K., Risma, K.A., Grom, A.A. \& Filipovich, A.H. (2011) Gene expression profiling of peripheral blood mononuclear cells from children with active hemophagocytic lymphohistiocytosis. Blood, 117, e151-60.

Tang, B.L. (2015) A unique SNARE machinery for exocytosis of cytotoxic granules and platelets granules. Molecular Membrane Biology, 32, 1464-5203.

Teramura, T., Tabata, Y., Yagi, T., Morimoto, A., Hibi, S. \& Imashuku, S. (2002) Quantitative analysis of cell-free Epstein-Barr virus genome copy number in patients with EBV-associated hemophagocytic lymphohistiocytosis. Leukemia and Lymphoma, 43, 173-179.

Terrell, C.E. \& Jordan, M.B. (2013) Perforin deficiency impairs a critical immunoregulatory loop involving murine $\mathrm{CD} 8(+) \mathrm{T}$ cells and dendritic cells. Blood, 121, 5184-5191.

Tesi, B., Chiang, S.C.C., El-Ghoneimy, D., Hussein, A.A., Langenskiöld, C., Wali, R., Fadoo, Z., Silva, J.P., Lecumberri, R., Unal, S., Nordenskjöld, M., Bryceson, Y.T., Henter, J.-I. \& Meeths, M. (2015a) Spectrum of atypical clinical presentations in patients with biallelic PRF1 missense mutations. Pediatric Blood \& Cancer, 62, 2094-2100

Tesi, B., Lagerstedt-Robinson, K., Chiang, S.C.C., Bdira, E.Ben., Abboud, M., Belen, B., Devecioglu, O., Fadoo, Z., Yeoh, A.E.J., Erichsen, H.C., Möttönen, M., Akar, H.H., Hästbacka, J., Kaya, Z., Nunes, S., Patiroglu, T., Sabel, M., Saribeyoglu, E.T., Tvedt, T.H., Unal, E., Unal, S., Unuvar, A., Meeths, M., Henter, J.-I., Nordenskjöld, M. \& Bryceson, Y.T. (2015b) Targeted high-throughput sequencing for genetic diagnostics of hemophagocytic lymphohistiocytosis. Genome Medicine, 7, 130-142.

Tesi, B., Sieni, E., Neves, C., Romano, F., Cetica, V., Cordeiro, A.I., Chiang, S., Schlums, H., Galli, L., Avenali, S., Tondo, A., Canessa, C., Henter, J.-I., Nordenskjöld, M., Hsu, A.P., Holland, S.M., Neves, J.F., Azzari, C. \& Bryceson, Y.T. (2015c) Hemophagocytic lymphohistiocytosis in 2 patients with underlying IFN- $\gamma$ receptor deficiency. The Journal of Allergy and Clinical Immunology, 135, 1638-41.

Usmani, G.N., Woda, B.a. \& Newburger, P.E. (2013) Advances in understanding the pathogenesis of HLH. British Journal of Haematology, 161, 609-622.

Vastert, S.J., van Wijk, R., D’Urbano, L.E., de Vooght, K.M.K., de Jager, W., Ravelli, A., Magni-Manzoni, S., Insalaco, A., Cortis, E., van Solinge, W.W., Prakken, B.J., Wulffraat, N.M., de Benedetti, F. \& Kuis, W. (2010) Mutations in the perforin gene can be linked to macrophage activation syndrome in patients with systemic onset juvenile idiopathic arthritis. Rheumatology, 49, 441-9.

Verbsky, J.W. \& Grossman, W.J. (2006) Hemophagocytic lymphohistiocytosis: diagnosis, pathophysiology, treatment, and future perspectives. Annals of Medicine, 38, 20-31.

Wang, Y., Wang, Z., Zhang, J., Wei, Q., Tang, R., Qi, J., Li, L., Ye, L., Wang, J. \& Ye, L. (2014) Genetic features of late onset primary hemophagocytic lymphohistiocytosis in adolescence or adulthood. PLoS One, 9, e107386.

Wang, Y., Ai, J., Xie, Z., Qin, Q., Wu, L., Liu, Y., Liu, C. \& Shen, K. (2015) IL-10-592 A/C polymorphisms is associated with EBV-HLH in Chinese children. Hematology. doi:10.1179/ 1607845415Y.0000000040

Xu, X.-J., Tang, Y.-M., Song, H., Yang, S.-L., Xu, W.-Q., Zhao, N., Shi, S.-W., Shen, H.-P., Mao, J.-Q., Zhang, L.-Y. \& Pan, B.-H. (2012) Diagnostic accuracy of a specific cytokine pattern in hemophagocytic lymphohistiocytosis in children. The Journal of Pediatrics, 160, e1.

Yanagimachi, M., Goto, H., Miyamae, T., Kadota, K., Imagawa, T., Mori, M., Sato, H., Yanagisawa, R., Kaneko, T., Morita, S., Ishii, E. \& Yokota, S. (2011a) Association of IRF5 polymorphisms with susceptibility to hemophagocytic lymphohistiocytosis in children. Journal of Clinical Immunology, 31, 946-51.

Yanagimachi, M., Naruto, T., Miyamae, T., Hara, T., Kikuchi, M., Hara, R., Imagawa, T., Mori, M., Sato, H., Goto, H. \& Yokota, S. (2011b) Association of IRF5 polymorphisms with susceptibility to macrophage activation syndrome in patients with juvenile idiopathic arthritis. The Journal of Rheumatology, 38, 769-74.

Yang, X., Hoshino, A., Taga, T., Kunitsu, T., Ikeda, Y., Yasumi, T., Yoshida, K., Wada, T., Miyake, K., Kubota, T., Okuno, Y., Muramatsu, H., Adachi, Y., Miyano, S., Ogawa, S., Kojima, S. \& Kanegane, H. (2015) A female patient with incomplete hemophagocytic lymphohistiocytosis caused by a heterozygous XIAP mutation associated with non-random X-chromosome inactivation skewed towards the wild-type XIAP allele. Journal of Clinical Immunology, 35, 244-8.

Zhang, K., Biroschak, J., Glass, D.N., Thompson, S.D., Finkel, T., Passo, M.H., Binstadt, B.A., Filipovich, A. \& Grom, A.A. (2008a) Macrophage activation syndrome in patients with systemic juvenile idiopathic arthritis is associated with MUNC13-4 polymorphisms. Arthritis and Rheumatism, 58, 2892-6.

Zhang, S., Ma, D., Wang, X., Celkan, T., Nordenskjöld, M., Henter, J.I., Fadeel, B. \& Zheng, C. (2008b) Syntaxin-11 is expressed in primary human monocytes/macrophages and acts as a negative regulator of macrophage engulfment of apoptotic cells and IgG-opsonized target cells. British Journal of Haematology, 142, 469479.

Zhang, K., Jordan, M.B., Marsh, R.A., Johnson, J.A., Kissell, D., Meller, J., Villanueva, J., Risma, K.A., Wei, Q., Klein, P.S. \& Filipovich, A.H. (2011) Hypomorphic mutations in PRF1, 
MUNC13-4, and STXBP2 are associated with adult-onset familial HLH. Blood, 118, 57945798.

Zhang, K., Chandrakasan, S., Chapman, H., Valencia, C.A., Husami, A., Kissell, D., Johnson, J.A \& Filipovich, A.H. (2014a) Synergistic defects of different molecules in the cytotoxic pathway lead to clinical familial hemophagocytic lymphohistiocytosis. Blood, 124, 1331-4.
Zhang, M., Behrens, E.M., Atkinson, T.P., Shakoory, B., Grom, A.A. \& Cron, R.Q. (2014b) Genetic defects in cytolysis in macrophage activation syndrome. Current Rheumatology Reports, 16, 439-446.

Zhang, M., Bracaglia, C., Prencipe, G., BemrichStolz, C.J., Beukelman, T., Dimmitt, R.A., Chatham, W.W., Zhang, K., Li, H., Walter, M.R., De Benedetti, F., Grom, A.A. \& Cron, R.Q.
(2016) A heterozygous RAB27A mutation associated with delayed cytolytic granule polarization and hemophagocytic lymphohistiocytosis. The Journal of Immunology, 196, 2492-503.

Zoller, E.E., Lykens, J.E., Terrell, C.E., Aliberti, J., Filipovich, A.H., Henson, P.M. \& Jordan, M.B. (2011) Hemophagocytosis causes a consumptive anemia of inflammation. The Journal of Experimental Medicine, 208, 1203-1214. 